\title{
IOGURTE COM POLPA E FARINHA DA CASCA DO ABACAXI
}

\author{
Yogurt of pulp and flour of pineapple bark
}

João Pedro Granjeiro Neres ${ }^{1}$, Rosane Liege Alves de Souza ${ }^{1}$, Camila Freitas Bezerra ${ }^{1 *}$

\section{RESUMO}

O presente trabalho teve como objetivo elaborar e caracterizar físico-quimicamente e sensorialmente um iogurte adicionado da farinha da casca de abacaxi. Foram elaboradas as formulações A (com adição de 1,5\% de farinha) e B (sem adição de farinha - controle). As formulações ainda foram comparadas a uma amostra $\mathrm{C}$ (iogurte comercial desnatado adicionado de aveia). A farinha da casca de abacaxi mostrou-se dentro da legislação para parâmetros importantes na conservação de farinhas vegetais. As maiores diferenças apresentadas por sua adição foram percebidas na análise sensorial. Apesar disso, o escore para o atributo sabor aproximou-se de "gostei moderadamente", justificando o índice de aceitabilidade maior que 70\%. As notas atribuídas podem ser devido ao baixo consumo de produtos com ingredientes de alegação funcional, como mostrou os dados de frequência de consumo. Diante dos resultados obtidos, o iogurte de abacaxi com adição da farinha de sua casca torna-se opção viável para aqueles que buscam dieta saudável, promovendo assim alternativa de expansão de produtos lácteos com alegações funcionais no mercado.

Palavras-chave: alimentos funcionais; Ananas comosus; cascas de frutas; derivados lácteos.

\begin{abstract}
This study aimed to develop and characterize physico-chemical and sensory pineapple yogurt added of its shell flour. Formulations A (with addition of $1.5 \%$ of flour) and B (without addition of flour - control) were prepared. These formulations were also compared to a sample $\mathrm{C}$ (low-fat yogurt added oats). The biggest differences presented by its addition were perceived in sensory analysis, nevertheless, the score for flavor attribute approached "like moderately", justifying the acceptability index
\end{abstract}

1 Instituto Federal de Educação, Ciência e Tecnologia do Rio Grande do Norte, BR 405, km 154, Bairro Chico Cajá, 59900-000, Pau dos Ferros, RN, Brasil. E-mail: bfmila@yahoo.com.br.

* Autor para correspondência.

Recebido / Received: 25/02/2016

Aprovado / Approved: 23/06/2016 
greater than $70 \%$. The marks awarded may be due to low consumer products with functional food ingredients, as shown by the consumption frequency data. Based on these results, yogurt pineapple with addition of its shell flour becomes a viable option for those seeking a healthy diet, promoting alternative expansion of dairy products with functional claims in the market.

Keywords: Ananas comosus; dairy products; fruit peels; functional foods.

\section{INTRODUÇ̃̃̃O}

O iogurte, alimento que tem como matéria prima o leite, é obtido via fermentação láctica, mediante ação de Lactobacillus bulgaricus e Streptococcus thermophilus, mostrando-se como produto de grande comercialização, devido suas características sensoriais. Possui vasta diversificação no mercado, em virtude de sua produção a partir do leite pasteurizado adicionado de cultura láctea e possibilidade de ser enriquecido com proteínas, vitaminas e minerais, isoladamente ou por meio do acréscimo de frutas na forma de pedaços, xaropes e geleias, dando assim sabor e aroma característicos ao produto final (PEREIRA et al., 2009; BRAGA et al., 2012; QUINTINO, 2012). No entanto, sabe-se que as cascas de frutas concentram muitos nutrientes. O reaproveitamento de partes não convencionais dos alimentos pode colaborar para a elaboração de novos produtos e matérias-primas, inclusive aqueles que já são bem aceitos pelos consumidores, transformando-os em opções de alimentos mais ricos nutricionalmente.

As farinhas de cascas de frutas já são produtos pesquisados e conhecidos, mas utilizados normalmente em biscoitos (PIOVESANA et al., 2013) e cookies (MENDES, 2013). Recentemente a alternativa de agregar farinha de cascas de frutas em iogurtes vem ganhando espaço e adeptos (GONÇALVES; LEÃO, 2013; VIEIRA et al., 2015). A casca do abacaxi (Ananas comosus) destaca-se pela presença de minerais $(4,74 \%$ base seca $)$ como cálcio, sódio, magnésio e potássio, como também pelo conteúdo de fibras $(17,92 \%$ base seca) (GONDIM et al., 2005). Estudos realizados acerca do abacaxi mostram que tanto a sua casca como o seu cilindro são fontes consideráveis de fibras alimentares como lignina, hemicelulose e celulose, concluindo-se, além disso, que sua casca fornece teores de nutrientes superiores à sua parte comestível (GONDIM et al., 2005; MENDES, 2013). Apesar da casca ser considerada fonte alternativa de nutrientes, a indústria alimentícia a descarta (OLIVEIRA, 2014) e a considera como resíduo industrial, porém, constatam-se as características funcionais e tecnológicas interessantes para o desenvolvimento de novos produtos.

Com o intuito de evitar o desperdício e na tentativa de agregar valor nutricional, esse trabalho teve como objetivo elaborar um iogurte com farinha de casca de abacaxi e analisar as características físico-químicas e sensoriais.

\section{MATERIAL E MÉTODOS}

\section{Obtenção da matéria-prima}

Para a elaboração do iogurte utilizouse frutos maduros obtidos na cidade do Encanto/RN, leite UHT (Ultra High Temperature), leite em pó integral e açúcar, adquiridos em supermercados da cidade de Pau dos Ferros/RN. A cultura láctea, constituída pelos microrganismos Streptococcus salivarius subsp. thermophilus e Lactobacillus delbrueckii supsb. bulgaricus, pertencentes à marca Rica Nata. 


\section{Produção da farinha da casca do abacaxi (FCA)}

Para a produção da farinha da casca do abacaxi seguiu-se a metodologia de Mendes (2013). Inicialmente, os frutos foram lavados com detergente neutro e então houve a separação da polpa das cascas. Em seguida, as cascas foram imersas em solução de 200 ppm de hipoclorito de sódio por 15 minutos. Passado este tempo, foram lavadas em água corrente para a retirada do excesso da solução clorada, trituradas e dispostas em fôrmas de alumínio cobertas por papel manteiga. A secagem ocorreu em estufa por $3 \mathrm{~h}$ a $60{ }^{\circ} \mathrm{C}$, seguindo-se de trituração em liquidificador industrial e posterior peneiramento. A polpa foi triturada, filtrada e armazenada em freezer a $-18{ }^{\circ} \mathrm{C}$ para uso no iogurte.

\section{Elaboração do iogurte}

Para a fabricação do iogurte foram utilizadas $0,01 \mathrm{~g} / \mathrm{L}$ de cultura láctea, conforme indicação do fabricante. Foram elaboradas as formulações A e B (controle), com e sem adição de farinha da casca de abacaxi, respectivamente (Tabela 1). Adicionalmente para fins comparativos, utilizou-se o iogurte desnatado adicionado de aveia de marca conhecida, identificado por C. Para elaborar as formulações, aqueceu-se o leite UHT a $45^{\circ} \mathrm{C}$, seguido da adição de leite em pó integral e incorporação da cultura láctea. A fermentação ocorreu por aproximadamente $6 \mathrm{~h}$ a $45^{\circ} \mathrm{C}$, finalizada pela medição do $\mathrm{pH}$ em aproximadamente 4,5 . Depois, o iogurte foi resfriado a temperatura de $10{ }^{\circ} \mathrm{C}$. A polpa do abacaxi, juntamente com o açúcar, foi aquecida em fogo médio até atingir consistência de calda, sendo acrescentada ao iogurte logo após a quebra da massa. Em seguida, a farinha da casca do abacaxi foi adicionada à formulação $\mathrm{A}$. Os iogurtes foram armazenados a $4{ }^{\circ} \mathrm{C}$ para posteriores análises.
Tabela 1 - Ingredientes dos iogurtes

\begin{tabular}{ccc}
\hline Ingredientes & \multicolumn{2}{c}{ Formulações } \\
$(\%)$ & $\mathrm{A}$ & $\mathrm{B}$ \\
\hline Leite integral & 66 & 66 \\
Leite em pó integral & 4 & 4 \\
Polpa de abacaxi & 15 & 15 \\
Açúcar & 13,5 & 13,5 \\
Farinha da casca do abacaxi & 1,5 & - \\
\hline
\end{tabular}

\section{Caracterização físico-química}

A farinha da casca do abacaxi e os iogurtes das formulações (A e B) desenvolvidas foram submetidos às análises físico-químicas, sendo realizada fabricação de três iogurtes para cada formulação. Foi determinado $\mathrm{pH}$ (obtido diretamente através do potenciômetro HI221 HANNA instruments), acidez titulável, umidade pelo método gravimétrico, cinzas conforme métodos 017/IV; 016/IV; 012/IV;0,18IV (IAL, 2008). A análise de lipídeos foi realizada por meio da metodologia de Folch (1957), utilizando como extrator o clorofórmio-metanol e estufa a $105^{\circ} \mathrm{C}$ para evaporação do solvente.

\section{Análise sensorial}

Foi realizada análise de aceitação por escala hedônica de 9 pontos, entre 1 (desgostei extremamente) a 9 (gostei muitíssimo), além da intenção de compra, com notas de 1 (certamente não compraria o produto) a 5 (certamente compraria o produto) (NORONHA, 2003). Na análise sensorial, 60 provadores não treinados, de ambos os sexos, alunos da instituição e na faixa etária de 14 a 21 anos de idade, responderam a um questionário de frequência de consumo, sobre o interesse em alimentos funcionais, como iogurte enriquecido por fibras. Utilizou-se amostras em copos descartáveis de $50 \mathrm{~mL}$ codificados com números aleatórios de 3 dígitos. Entre os atributos estiveram 
cor, aparência, aroma, textura e sabor. Determinou-se o índice de aceitação dos produtos de acordo com IA $=$ A x100/B; onde $\mathrm{A}=$ nota média obtida para o iogurte em determinado atributo e $\mathrm{B}=$ nota máxima dada ao iogurte naquele atributo. Valores iguais ou superiores a $70 \%$ indicam boa aceitação (DUTCOSKY, 2007).

\section{Análise estatística}

O software Graph Pad Prism versão 5.0 forneceu a análise de variância (ANOVA) para os resultados físico-químicos e sensoriais. $\mathrm{O}$ teste de Tukey foi aplicado como critério de validação de significância estatística a um nível de confiança de $95 \%$.

\section{RESULTADOS E DISCUSSÃO}

\section{Análises físico-químicas}

As análises físico-químicas da casca do abacaxi, amostras do iogurte elaborado e comercial encontram-se na Tabela 2. De modo geral, a umidade é um dos parâmetros que afeta diretamente na perecibilidade, sendo assim o baixo teor obtido para a FCA contribui para maior vida útil. Tanto a umidade quanto o teor de cinzas, encontram-se dentro do esperado pela legislação que preconiza um máximo de 15 e $4 \%$, respectivamente, para farinhas vegetais (BRASIL, 1978).

Avaliando as três formulações, o pH apresentou diferença significativa $(\mathrm{p}<0,05)$. De acordo com a legislação brasileira, não é estabelecido valor exato para iogurtes, porém a $I N n^{\circ} 46$ do MAPA, recomenda que após 48 horas do processo de fermentação o $\mathrm{pH}$ deve estar situado em faixa média de 3,5 a 4,6 (BRASIL, 2007). Os valores obtidos para os iogurtes encontram-se dentro da faixa recomendada, exceto a formulação B que apresentou média superior ao limite preconizado. Martin (2002) afirma que, normalmente são encontrados iogurtes com pH correspondentes ao intervalo de 3,7 e 4,6, entretanto, iogurtes com valores entre 4,0 e 4,4 são considerados melhores pelo consumidor, já que estes apresentam sabor menos ácido ou menos amargo. $\mathrm{O} \mathrm{pH}$ do iogurte $\mathrm{B}$ ficou um pouco acima do recomendado, entretanto não alterou as características sensoriais do mesmo, visto que o ponto isoelétrico da caseína é por volta de 4,6-4,7 no qual ocorre a coagulação favorecendo as características de viscosidade do iogurte. No que se refere ao parâmetro acidez, as formulações dos iogurtes A e B estão dentro dos parâmetros exigidos pela legislação, que estabelece \% em ácido láctico de 0,6 a 2,0\% (BRASIL, 2007). Como era de se esperar, o iogurte $\mathrm{C}$, apresentou média inferior às formulações elaboradas, com valor de $0,56 \%$, visto que o $\mathrm{pH}$ obtido anteriormente foi de 4,33. Deve-se levar em conta que a amostra $\mathrm{C}$ trata-se de produto comercial, onde as análises foram realizadas em tempo superior ao recomendado.

A umidade e cinzas são também variáveis que não possuem valores previstos na $\mathrm{IN} \mathrm{n}^{\circ} 46$ para produtos lácteos fermentados. No entanto, apesar da adição da FCA à formulação A, não houve diferenças estatísticas em relação à amostra B, provavelmente decorrente da baixa concentração de farinha adicionada (1,5\%). Quanto as cinzas, entre a amostra A e B, não se percebeu diferença estatística, mas destacase quando comparadas a C. Pode-se inferir que o abacaxi é desejável quando objetiva-se aumentar o valor mineral, conforme comprova Gondim et al. (2005) e Santos et al. (2010).

O percentual de lipídeos das formulações A e B encontram-se abaixo do exigido pela legislação vigente, sendo atribuída a matériaprima utilizada. Como consequência do processo de desnate, a amostra $\mathrm{C}$ apresenta conteúdo máximo de $0,5 \%$.

\section{Análise sensorial}

A pesquisa sobre a frequência de consumo (Figura 1) de produtos com alegação 
de propriedades funcionais revelou que os jovens ainda não têm preocupação com a saúde, e que suas escolhas alimentares podem ser influenciadas pelos grupos a qual fazem parte. Além disso, os padrões alimentares dos adolescentes são normalmente caóticos, associado ao consumo de fast-foods, refrigerantes e alimentos gordurosos (KRAUSE et al., 2012).

A cor e aparência representam os primeiros atributos nos quais o consumidor terá contato (TEIXEIRA, 2009), fornecendo a impressão imediata, refletindo diretamente no julgamento e na opinião sobre o alimento analisado. Nota-se que a formulação A não apresentou diferença estatística em relação à formulação C (bem aceita no mercado) para estes dois atributos (Tabela 3). Em iogurte adicionado de farinha da casca da jabuticaba, a proporção de $1,5 \%$, a mesma utilizada neste trabalho, parece favorecer a cor e aparência, com média na análise sensorial de 6,94 e 6,96, respectivamente (ALVES, 2011).

Segundo Biedrzycki (2008), o aroma é

Tabela 2 - Análises físico-químicas dos iogurtes

\begin{tabular}{c|c|c|c|c|c|c}
\hline Parâmetro & FCA & A & B & C & $\begin{array}{c}\text { Legislação } \\
\text { para iogurte } \\
\text { integral }\end{array}$ & $\begin{array}{c}\text { Legislação } \\
\text { para iogurte } \\
\text { desnatado }\end{array}$ \\
\hline $\mathrm{pH}$ & - & $4,60^{\mathrm{b}} \pm 0,01$ & $4,74^{\mathrm{a}} \pm 0,03$ & $4,33^{\mathrm{c}} \pm 0,02$ & - & - \\
Acidez (\%)) & - & $0,70^{\mathrm{a}} \pm 0,02$ & $0,63^{\mathrm{a}} \pm 0,02$ & $0,56^{\mathrm{b}} \pm 0,02$ & $0,6-2,0$ & $0,6-2,0$ \\
Umidade (\%) & $10,60 \pm 0,00$ & $75,20^{\mathrm{a}} \pm 0,14$ & $77,60^{\mathrm{a}} \pm 0,42$ & $82,05^{\mathrm{a}} \pm 2,90$ & - & - \\
Cinzas (\%) & $3,45 \pm 0,16$ & $0,55^{\mathrm{a}} \pm 0,00$ & $0,47^{\mathrm{a}} \pm 0,06$ & $0,20^{\mathrm{b}} \pm 0,49$ & - & - \\
Lipídeos (\%) & - & $2,65^{\mathrm{a}} \pm 0,21$ & $2,25^{\mathrm{a}} \pm 0,92$ & $0,50^{\mathrm{b}} \pm 0,14$ & Mín. 3,0 & Máx. 0,5 \\
\hline
\end{tabular}

Valores expressos como média \pm desvio padrão.

Letras diferentes na mesma linha diferem entre si pelo teste de Tukey a 5\% de probabilidade.

Formulação A - com adição da farinha da casca do abacaxi; Formulação B (controle) - sem adição da farinha e Formulação $\mathrm{C}$ - iogurte comercial desnatado com adição de aveia.

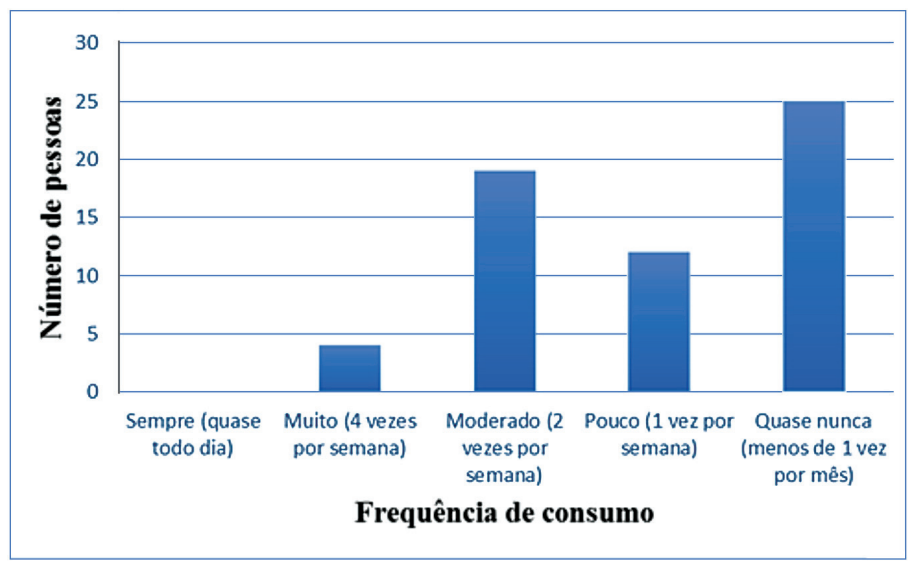

Figura 1 - Frequência de consumo de alimentos com alegação de propriedades funcionais 
um importante atributo sensorial que correlaciona o olfato ao paladar, não se restringindo apenas ao nariz, mas sim a todo o sistema nasal, incluindo a boca. Assim, o consumidor tende a relacionar o aroma do produto diretamente à matéria-prima utilizada em sua fabricação. Nesta perspectiva, existiu diferença significativa entre a amostra A e B (controle), sugerindo que a casca teve influência no aroma e alterando os escores de "gostei ligeiramente" para "gostei moderadamente", respectivamente. Freire (2012) encontrou neste quesito para seu iogurte adicionado da farinha do albedo de maracujá média de 7,71.

Apesar da diferença estatística entre A e B no atributo textura, Vieira et al. (2015) chama a atenção de que em iogurtes, a adição da casca do maracujá melhorou a capacidade de retenção de água, diminuindo a sinérese, tão indesejável entre os consumidores.

Com relação ao sabor, a maior média apresentou-se para a formulação sem FCA. Apesar disso, Gonçalves; Leão (2013) obtiveram menores índices para esse atributo, apresentando média de 5,59 para iogurtes com adição de farinhas mistas a partir dos resíduos de maçã, maracujá e uva.

Tabela 3 - Parâmetros sensoriais para as amostras de iogurtes

\begin{tabular}{c|c|c|c}
\hline Atributos & $\mathrm{A}$ & $\mathrm{B}$ & $\mathrm{C}$ \\
\hline Cor & $6,8^{\mathrm{b}} \pm 1,77$ & $7,8^{\mathrm{a}} \pm 1,16$ & $7,3^{\mathrm{a}} \pm 1,34$ \\
Aparência & $6,7^{\mathrm{b}} \pm 1,69$ & $8,0^{\mathrm{a}} \pm 1,06$ & $7,3^{\mathrm{b}} \pm 1,43$ \\
Aroma & $6,6^{\mathrm{b}} \pm 1,84$ & $7,7^{\mathrm{a}} \pm 1,21$ & $6,9^{\mathrm{b}} \pm 1,64$ \\
Textura & $6,5^{\mathrm{b}} \pm 2,42$ & $7,9^{\mathrm{a}} \pm 1,52$ & $6,4^{\mathrm{b}} \pm 2,07$ \\
Sabor & $6,8^{\mathrm{b}} \pm 1,92$ & $8,1^{\mathrm{a}} \pm 1,41$ & $6,9^{\mathrm{b}} \pm 1,88$ \\
\hline
\end{tabular}

Valores expressos como média \pm desvio padrão.

Letras diferentes na mesma linha diferem entre si pelo teste de Tukey a 5\% de probabilidade.

Formulação A - com adição da farinha da casca do abacaxi; Formulação B (controle) - sem adição da farinha e Formulação $\mathrm{C}$ - iogurte comercial desnatado com adição de aveia.
Apesar da formulação B ter apresentado notas maiores em todos os quesitos sensoriais analisados, a formulação A foi bem aceita pelos provadores, com índice de aceitabilidade acima de $70 \%$ (Tabela 4 ). Os resultados encontrados para intenção de compra (Tabela 4) confirmam os resultados já discutidos. As amostras A e C foram consideradas medianas, representando na escala "talvez comprasse/ talvez não comprasse". A formulação A (com adição de farinha) não foi a preferida pelos avaliadores, no entanto, Lucia (2008) defende que a implementação de ingredientes funcionais aos alimentos é vista de forma positiva pelo consumidor, o que intensifica sua comercialização. Possivelmente, a avaliação de intenção de compra para a referida formulação seria melhor se informações sobre os benefícios associados à FCA tivessem sido disponibilizadas.

Tabela 4 - Índice de aceitabilidade e intenção de compra das amostras de iogurte

\begin{tabular}{c|c|c|c}
\hline Atributos & A & B & C \\
\hline Cor (\%) & 75 & 86 & 81 \\
Aparência (\%) & 74 & 88 & 81 \\
Aroma (\%) & 73 & 85 & 76 \\
Textura (\%) & 72 & 87 & 71 \\
Sabor (\%) & 75 & 90 & 76 \\
Intenção de compra & 3,4 & 4,4 & 3,3 \\
\hline
\end{tabular}

Formulação A - com adição da farinha da casca do abacaxi; Formulação B (controle) - sem adição da farinha e Formulação C - iogurte comercial desnatado com adição de aveia.

\section{CONCLUSÕES}

Mediante os resultados foi possível comprovar a viabilidade da adição de farinha de casca do abacaxi em iogurte. A FCA apresentou-se dentro dos padrões exigidos pela legislação garantindo boa conservação e maior vida útil. A farinha vegetal não alterou as características físico-químicas do 
iogurte. Houve diferença na análise sensorial do iogurte adicionado da farinha da casca de abacaxi, no entanto, o índice de aceitabilidade para a formulação A foi acima de $70 \%$.

\section{REFERÊNCIAS}

Alves, A. P. C. Casca de Jabuticaba (Pliniajaboticaba (Vell.) Berg): processo de secagem e uso como aditivo em iogurte. 2011. 90f. Dissertação (Mestrado em Agroquímica) - Universidade Federal de Lavras, Lavras, 2011.

BIEDRZYCKI, A. Aplicação da avaliação sensorial no controle de qualidade em uma indústria de produtos cárneos. 2008. 64f. Monografia (Especialização em Engenharia de Alimentos ) - Universidade Federal do Rio Grande do Sul, Porto Alegre, 2008.

BRAGA, A. C. C.; NETO, E. F. A.; VILHENA, M. J. V. Elaboração e caracterização de iogurtes adicionados de polpa e de xarope de Mangostão. Revista Brasileira de Produtos Agroindustriais, v. 14, n. 1, p. 77-84, 2012.

BRASIL. Resolução n 12, de julho de 1978. Aprova NORMAS TÉCNICAS ESPECIAIS, do Estado de São Paulo, revistas pela CNNPA, relativas a alimentos (e bebidas), para efeito em todo território brasileiro. Diário Oficial da República Federativa do Brasil, Brasília, 24 jul. 1978. Seção 1, p. I.

BRASIL. Instrução Normativa $n^{\circ}$ 46, de 23 de outubro de 2007. Aprova o Regulamento Técnico de Identidade e Qualidade de Leites Fermentados. Diário oficial da República Federativa do Brasil, Brasília, DF, 24 out. 2007. Seção 1, p. 4.

DUTCOSKY, S. D. Análise sensorial de alimentos. Curitiba: Editora Champagnat, 2007. $239 \mathrm{p}$.
FOLCH, J.; LESS, M.; STANLEY, S. A simple method for the isolation and purification of total lipids from animal tissues. Journal Biological Chemistry, v. 226, n. 1, p. $497-$ $509,1957$.

FREIRE, V. A. P. Viabilidade de culturas probióticas de Lactobacillus spp.e Bifidobacterium spp. em iogurte adicionado de polpa e farinha do albedo de maracujá (Passiflora edulis). 2012. 141f. Dissertação. (Mestrado em Ciência e Tecnologia Agroindustrial) - Universidade Federal de Pelotas, Pelotas, 2012.

GONÇALVES, C. R.; LEÃO, M. F. Produção de iogurte com adição das farinhas mistas a partir dos resíduos de maçã, maracujá e uva. Revista Enciclopédia Biosfera, v. 9, n. 17, p. $3618-3631,2013$.

GONDIM, J. A. M. et al. Composição centesimal e de minerais em cascas de frutas. Ciência e Tecnologia de Alimentos, v. 25, n. 4, p. 825-827, 2005.

INSTITUTO ADOLFO LUTZ. Métodos físico-químicos para análise de alimentos. $4^{\mathrm{a}}$ ed., $1^{\mathrm{a}}$ ed. digital. São Paulo: Instituto Adolfo Lutz, 2008. 1018 p.

KRAUSE, L. et al. Alimentos, nutrição e dietoterapia. Rio de Janeiro: Elsevier, 2012. $1227 \mathrm{p}$.

LUCIA, S. M. D. Métodos estatísticos para avaliação da influência de características não sensoriais na aceitação, intenção de compra e escolha do consumidor. 2008. 135f. Dissertação (Mestrado em Ciência e Tecnologia de Alimentos) - Universidade Federal de Viçosa, Viçosa, 2008.

MARTIN, A. F. Armazenamento do iogurte comercial e o efeito na proporção das 
bactérias lácticas. 2002. 62f. Dissertação. (Mestrado em Ciência e Tecnologia de Alimentos) - Universidade de São Paulo, Piracicaba, 2002.

MENDES, B. A. B. Obtenção, caracterização e aplicação de farinha das cascas de abacaxi e de manga. 2013. 77f. Dissertação. (Mestrado em Engenharia de Alimentos) Universidade Estadual do Sudoeste da Bahia, Itapetinga, 2013.

NORONHA, J. F. Apontamentos de analise sensorial. Coimbra, 2003. Disponível em: $<$ http:// www.esac.pt/noronha/A.S/Apontamentos/ sebenta_v_1_0.pdf $>$, Acesso em: 06 dez. 2015.

OLIVEIRA, A. S. B. Estudo da secagem de casca de abacaxi visando desenvolvimento de chá a partir do produto seco. 2014. 82f. Dissertação. (Mestrado em Ciências e Tecnologias Agropecuárias) - Universidade Estadual do Norte Fluminense Darcy Ribeiro, Goytacazes, 2014.

PEREIRA, E. D. et al. Caracterização de iogurte elaborado a partir de leite de cabra acrescido com polpa de uvaia (Eugenia uvalhacambess). 2009. Bambuí. Disponível em: <http://www.cefetbambui.edu.br/sct/ trabalhos/Produ \%C3\%A7\%C3\%A30\%20 Aliment $\%$ C3\%ADcia/101-PT-7.pdf>. Acesso em: 27 jul. 2015.
PIOVESANA, A.; BUENO, M. M.; KLAJN, V. M. Elaboração e aceitabilidade de biscoitos enriquecidos com aveia e farinha de bagaço de uva. Brazilian Journal of Food Technology, v. 16, n. 1, p.68-72, 2013.

QUINTINO, S. S. Avaliação comparativa de iogurte produzido a partir da polpa natural de maracujá (Passiflora edulisSims f. flavicarpaDeg.) e suco artificial. Revista Enciclopédia Biosfera, v. 8, n. 14, p. 18301842, 2012.

SANTOS, A. R. R. et al. Avaliação da composição centesimal de casca de abacaxi. In: III SEMINÁRIO DE INICIAÇÃO CIENTÍFICA E INOVAÇÃO TECNOLÓGICA, 3., 2010, Rio Pomba. Anais eletrônicos... Rio Pomba: IF Sudeste MG, 2010. Disponível em: <http://iftm.edu.br/SITES/proreitorias/ pesquisa/3o_seminario/trabalhos/ali avaliacao_da_composicaoo_centesimal.pdf $>$ Acesso em: 20 de fev. 2016.

TEIXEIRA, L. V. Análise sensorial na indústria de alimentos. Revista do Instituto de Laticínios Cândido Tostes, v. 64, n. 366, p. 12-21, 2009.

VIEIRA, N. F. et al. Physicochemical and sensory profile of yogurt added with passion fruit peel flour. African Journal Biotechnology, v. 14, n. 2, p. 149-155,2015. 